\title{
Phytopathology
}

\section{Historical Perspectives, Management, and Current Research of Citrus HLB in Guangdong Province of China, Where the Disease has been Endemic for Over a Hundred Years}

\author{
Zheng Zheng, Jianchi Chen, ${ }^{\dagger}$ and Xiaoling Deng ${ }^{\dagger}$
}

First and third authors: Laboratory of Citrus Huanglongbing Research, Department of Plant Pathology, South China Agricultural University, Guangzhou, China; and second author: San Joaquin Valley Agricultural Sciences Center, United States Department of AgricultureAgricultural Research Service, Parlier, CA.

Accepted for publication 25 August 2018.

\begin{abstract}
Citrus huanglongbing (HLB) is a highly destructive disease currently threatening citrus production worldwide. In China, the disease is exclusively associated with 'Candidatus Liberibacter asiaticus', a nonculturable proteobacterium. HLB was observed in Guangdong of China over a hundred years ago. Researchers and citrus growers have been battling with the disease through vigorous research and have exercised various control practices. Much of the early work was not well known outside China. This review is intended to fill in gaps of historical information by reviewing selected literature records. Along the way, the HLB system within southern China was evaluated. Emphases were on comparison of symptomatology, evolution of etiology, control practices, and impacts of using next-generation sequencing technology for ' $\mathrm{Ca}$. L. asiaticus' research and detection.
\end{abstract}

Citrus huanglongbing (HLB) (also known as citrus greening disease) is a highly destructive disease currently threatening citrus production worldwide. Although Koch's postulates have not been fulfilled (Chen et al. 2011), the research community in general agrees that HLB is associated with or caused by (based on strong association and molecular evidence) three noncultivable proteobacteria: 'Candidatus Liberibacter asiaticus', ' $\mathrm{Ca}$. L. africanus' (Jagoueix et al. 1994), and ' $C a$. L. americanus' (Teixeira et al. 2005). Among them, ' $\mathrm{Ca}$. L. asiaticus' is the most prevalent and the only species found and confirmed in Asia and North America. In Brazil, both ' $C a$. L. asiaticus' and ' $C a$. L. americanus' were found (Coletta-Filho et al. 2004; Teixeira et al. 2005). However, ' $C a$. L. americanus' has been diminishing (Lopes et al. 2009). In addition to Liberibacters, several phytoplasmas have been detected in citrus showing HLB symptoms (Arratia-Castro et al. 2014; Chen et al. 2009; Das et al. 2016; Lou et al. 2014; Teixeira et al. 2008).

The term "huanglongbing" is in Pinyin, the official Romanization system for standard Chinese, representing three Chinese

${ }^{\dagger}$ Corresponding authors: J. Chen; E-mail: Jianchi.chen@ars.usda.gov; and X. Deng; E-mail: xldeng@scau.edu.cn

Funding: This study was supported by Chinese Modern Agricultural Technology Systems (CARS-26), the National Key Research and Development Program of China (2018YFD0201500), and California Citrus Research Board.

(C) 2018 The American Phytopathological Society characters: 黄龙病 (i.e., huang, long, and bing, respectively). The character "huang" means yellow and "bing" means disease. The second character, "long", literally means dragon. However, Chinese language is multidialectal. In the dialect of Chaoshan, where HLB was first described, character 龙 (dragon) and 梢 (young shoot) are homophonic. Therefore, "huanglongbing" should be designated "yellow shoot disease" (Lin 1956a), which makes sense, rather than "yellow dragon disease", which does not make sense. HLB symptoms are complex, with many different names. However, the main characteristic is general yellowing (or 黄 [huang]) of leaves. In Guangdong, symptoms of HLB were commonly grouped into three types: yellowing, mottling, and Zn-deficiency-like (Fig. 1) for the convenience of description. Intermediate and mixed types are also commonly found.

Concern about HLB has increased significantly since the mid2000s, when the disease was found in Brazil and the United States (Coletta-Filho et al. 2004; Halbert 2005; Kumagai et al. 2013; Kunta et al. 2012; Teixeira et al. 2005), two major citrus producers in the world. China also is a major producer of citrus. HLB has occurred in southern China for more than a hundred years. Over this time, there has been vigorous research and control practice development to battle the disease. Much Chinese research and many management strategies, especially those before the millennium, remain little known outside China.

This review is not intended to be a comprehensive collection of HLB research literature. An excellent and extensive historical and literature review of HLB in China has recently been published 
(Zhao 2017). Instead, we selected representative publications for discussion with the following goals: (i) to review the historical perspectives of HLB in southern China, focusing in Guangdong, where the majority of research has occurred; (ii) to reveal and analyze examples of HLB control practices in China for reference to current worldwide HLB control efforts; and (iii) to discuss what has been done and what can be done to meet the challenge of HLB research and management.

\section{EARLY HLB RECORDS IN GUANGDONG}

China has an over 4,000-year history of citriculture. In the Guangdong region (Fig. 2), citrus cultivation started later but at least 2,000 years ago (Gan and Tang 2013). Guangdong has remained an important citrus producer through the years. With regard to the last century, a review on citrus culture in Guangdong (Jiang et al. 1935b) listed eight locations where citrus cultivation was highly developed-Chaoan (潮安), Xinhui (新会), Panyu (番禺), Chaoyang (潮 阳), Rouping (饶平), Sihui (四会), Zhongshan (中山), and Shunde (顺德) - all in the Pearl River Delta and Chaoshan areas (also called Hanjiang Delta) (Fig. 2). Tonnage of citrus exports from Guangdong from 1925 to 1934 is listed in Table 1. The large amount of citrus exports up to 1933 indicated strong citrus production at the time. However, a $>50 \%$ drop occurred in 1934 in both Shantou (representing Chaoshan area) and Guangzhou, Jiangmen, and Gongbei (representing the Pearl River Delta area). [Note: The first author of Jiang Zhi (江秩) in the article by Jiang et al. (1935b) was Ira J. Condit. Dr. Condit was a horticulturist and visiting professor in Lingnan University in Guangdong from 1934 to 1935, and late professor of the University of California at Riverside. The manuscript was originally written in English and translated and edited by coauthor H. C. Wang (王浩真), an assistant researcher in Lingnan University.]

It was and still is a puzzle as to when HLB first occurred in China. In his 1956 publication, Professor Lin Kong-Hsiang (林孔湘) of South China Agricultural College reported his conversation with citrus growers in Chaoshan of Guangdong (Lin 1956a). A grower told him that HLB was observed 70 to 80 years ago. With this as a reference, observation of HLB in the Chaoshan area could be dated to the 1870s. Given the long and successful citrus cultivation in Guangdong and neighboring provinces, and no mention of any devastating disease, it could be speculated that HLB was introduced from outside China. If so, Hongkong and Macau, the two active foreign trade ports by then, could be suspected points of entry. Alternatively, HLB could be endogenous. To understand which of these possibilities is correct requires more research to provide conclusive scientific evidence.

\section{OBSERVATION OF "YELLOWING" AND "MOTTLED LEAF" DISEASES}

Professor O. A. Reinking was probably the first plant pathologist to report possible HLB in China (Reinking 1919). Dr. Reinking, the late professor of Cornell University, was on the faculty of the University of the Philippines and headed the Department of Plant Pathology from 1916 to 1921 . With the co-operation of the Crop Physiology and Breeding Investigations Unit of the Bureau of Plant Industry (the forerunner of the United States Department of Agriculture-Agricultural Research Service), Prof. Reinking made a plant disease survey from May to June 1919. He visited the agricultural regions of the Pearl River Delta of Guangdong (Kwang Tung) Province around Guangzhou (Canton), Macau, and Hong Kong, and also Guangxi (Kwang Si) Province along the West River (the west branch of Pearl River) (Fig. 2).

In the 30-page report, Reinking described two diseases under the section on orange (Citrus sinensis Osbeck) that could be HLB based on symptomatology. (i) Yellowing. This was observed in citrus trees growing under poor soil conditions and in heavily intercropped areas. (ii) Mottled leaf. The disease had definite yellowed areas between the green-colored main veins of leaves. Descriptions of the two diseases were brief and without photographic documentation. The two diseases were not reported in other citrus cultivars or

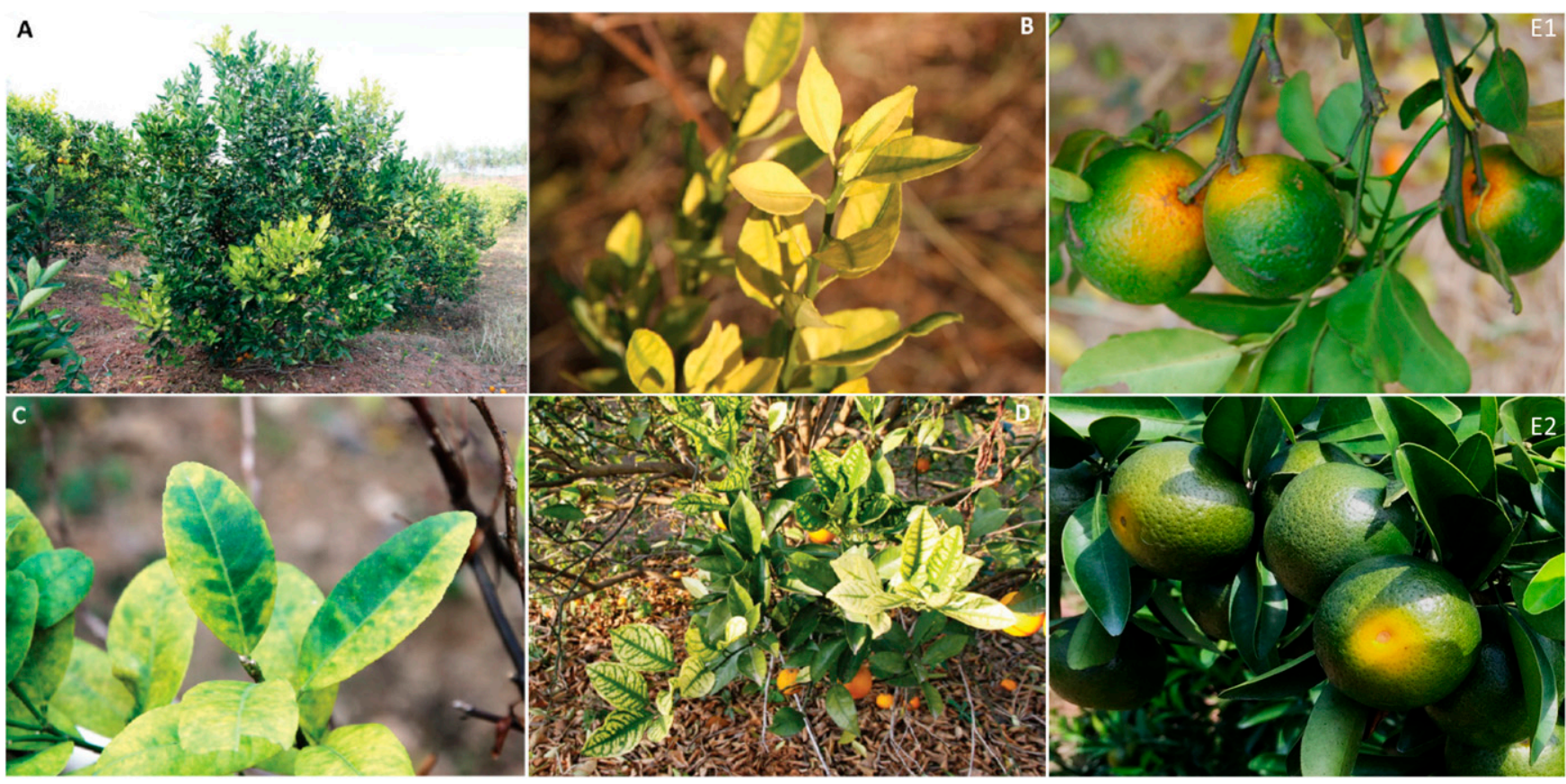

FIGURE 1

Major symptom types of citrus huanglongbing in Guangdong, China. A, Yellow shoots; B, leaf evenly yellowing; C, leaf mottling; and D, Zn-deficiencylike (Chen et al. 2011). E1, Red-nose fruit of Shatangju (Citrus reticulata) with color change started from stem end and E2, normal fruit of Shatangju with color change started from flower end. 
species. There was no mention of Asian citrus psyllid (ACP) (Diaphorina citri), the insect vector that spreads HLB. [Note: ACP was first described in Taiwan (Kuwayama 1907). The insect was also recorded under the name of Euphalerus citri in Macau in 1906 and in Hong Kong in 1908 (Crawford 1919; Martin and Lau 2011). Jiang et al. (1935a) reported the presence of ACP in Chaoshan but did not consider it as an important pest. ACP was later shown to transmit HLB pathogens in Guangdong, China (Guangdong Agriculture and Forestry College 1977)].

\section{HLB OUTBREAKS IN 1930S AND SYMPTOMATOLOGY}

Literature records (He 1937; Jiang et al. 1935b; Tu 1932) indicate that there was a serious outbreak of HLB throughout the citrusgrowing areas in Guangdong in the 1930s. Limited by available technology, symptoms of HLB were exclusively described by writing. Limited black and white photographs were published but the quality was generally low based on today's standards. Therefore, much of the original symptom descriptions are literarily cited here in the hope of providing the most accurate information for analyses.

Prof. C. Tu (涂治) of Plant Pathology in Lingnan University performed a citrus disease survey in fall 1930 (Tu 1932). He raised a concern about the future of citriculture in Guangdong because of a dreadful malady of "yellowing" disease. He also reported a mottled leaf disease as a different disease described by Reinking (1919). The yellowing disease was described as such: "The trees so affected become sickly looking and much stunted. Usually the leaves have a pale, yellowish cast. At first the twigs gradually die back. In the more advanced stage, there is considerable defoliation especially during the dry seasons. Finally, the tree dies at the age of its greatest fruitfulness" (Tu 1932). Two photographs of yellowing disease in sweet orange were presented, one tree severely defoliated and the other with rotted roots (Fig. 3A and B). "Yellowing was linked to poor development in root systems. The fibrous roots were usually sloughed off. The main roots became rotten and got broken, and the lateral roots were much blackened." This was probably the first record description of HLB as a root rot disease. Mottled leaf was listed as a problem after yellowing. Sweet orange ( $C$, sinensis) was more susceptible than mandarin $(C$. reticulate). Diseased leaves showed characteristic mottling (Fig. 3C but not clear). "The disease usually spread from the top downwards. In the advanced stage, the twigs might die back. Sometimes, multiple buds were formed. Later, considerable defoliation occurred." Prof. Tu mentioned two additional symptoms, smaller leaves and untimely flowers (Fig. 3C).

In his review of citrus culture in Guangdong, Jiang et al. (1935b) noted that the citrus production cycle was getting shorter and shorter. He also used the term root rot to describe HLB, and

TABLE 1

Records of citrus export in the unit of Dan (approximately $60 \mathrm{~kg}$ ) in four cities in Guangdong Province between 1925 and 1934 (Jiang et al. 1935b)

\begin{tabular}{ccccc}
\hline Year & Shantou & Guangzhou & Jiangmen & Gongbei \\
\hline 1925 & 193,935 & 11,959 & 11,326 & 3,063 \\
\hline 1926 & 192,200 & 11,792 & 15,010 & 1,814 \\
\hline 1927 & 224,341 & 8,975 & 33,276 & 5,196 \\
\hline 1928 & 248,333 & 8,604 & 36,601 & 15,351 \\
\hline 1929 & 270,482 & 10,020 & 15,319 & 24,987 \\
\hline 1930 & 235,469 & 17,468 & 18,452 & 17,430 \\
\hline 1931 & 220,786 & 24,215 & 43,675 & 6,294 \\
\hline 1932 & 109,450 & 9,911 & 61,111 & 7,001 \\
\hline 1933 & 126,518 & 10,894 & 84,898 & 5,830 \\
\hline 1934 & 60,379 & 5,039 & 52,488 & 3,829 \\
\hline
\end{tabular}
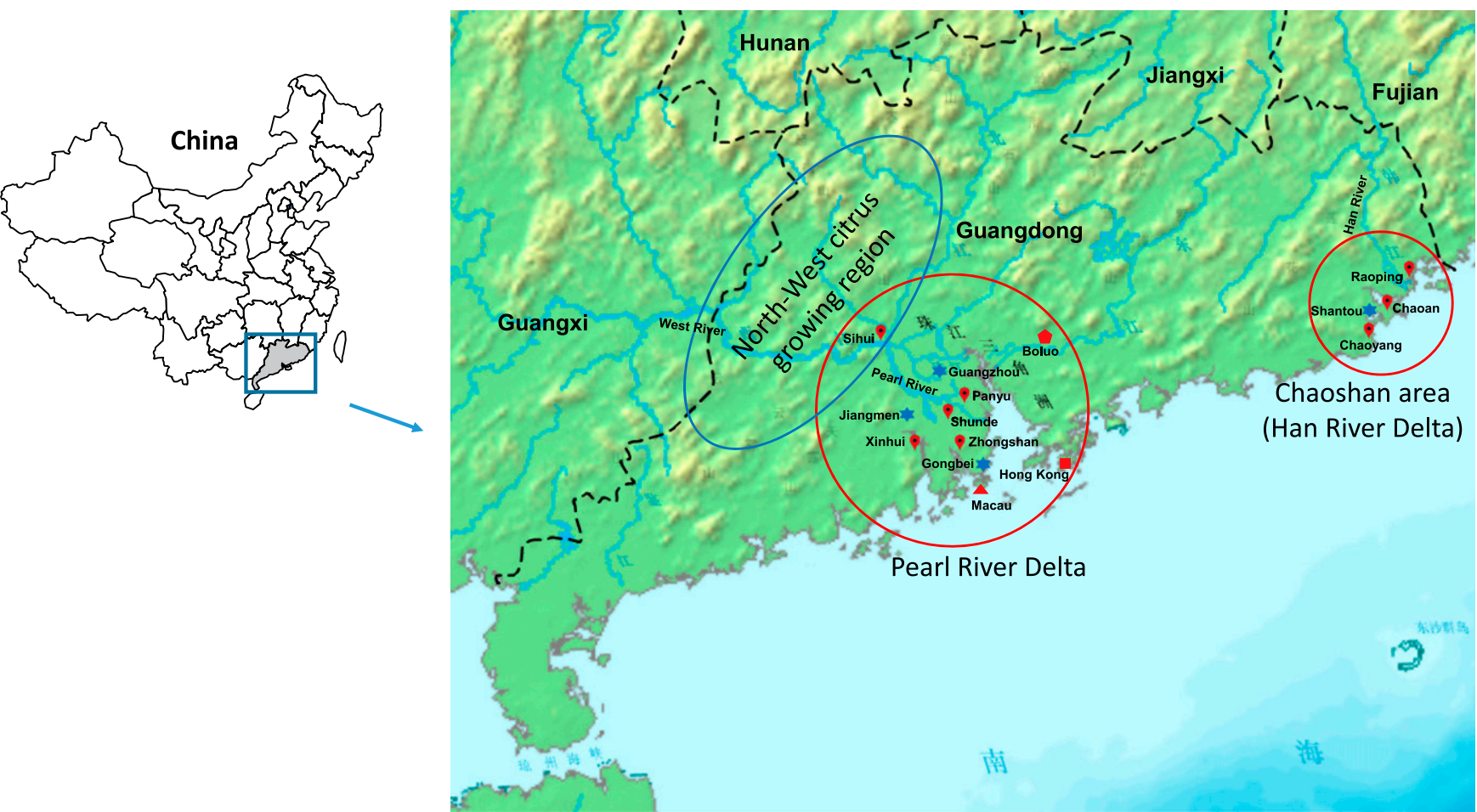

FIGURE 2

Topology map of Guangdong and neighboring provinces in southern China. Three major citrus production areas at present and in the past are circled. Red circles indicate major citrus planting regions before the 1990s. The blue circle is the major citrus production region since the mid-1990s. 
mentioned other synonyms, chicken-head yellow in Guangzhou (Pearl River Delta area) and huanglong (yellow shoot) in the Chaozhou area. HLB was widespread in both nurseries and production orchards. Infected nursery stocks could not even reach the stage of flowering and fruiting, and died. The description said, "When mature trees were infected, initially, only one or two citrus shoots started to turn yellow. As winter arrived, number of yellow leaves increased and some defoliated. In spring, tree budbreaking very early and over-bloomed." This, again, mentioned the affect on citrus blooming. "Fruits did not develop well. Trees withered before reaching fall. Examination of dead trees showed symptoms of black rot. Partial rotting was also found in lightly yellowing trees."

Another plant pathologist, Prof. W. He (何畏冷) of Lingnan University reported a root rot disease of citrus during his visit in Chaoshan in 1935 (He 1937). Prof. He wrote, "When the tree gets affected, rootstocks did not show symptoms in the first year. After planting, yellow leaves started to show. In 4 years, the whole tree showed yellowing of leaves, withering, and easily dropped with light tapping of the tree. Tree branches dieback and root rotten with cortex peeling off, woody tissue blacken and emitted foul smell." Citrus yellowing and mottling were also observed in the neighboring province of Guangxi (Huang 1943) and was named as pepper leaf disease.

As the HLB epidemic escalated, Prof. Chen Che Poh (陈其儤), a plant pathologist in Fukien (Fujian) Provincial Agricultural College, was appointed by the government to investigate the disease. Prof. Chen's work did not come easy because it was in the middle of World War II. Risking air strikes and other support difficulties, he conducted a 4-year study in the Chaoshan area of Guangdong from 1938 to 1941. He translated HLB as tipchlorosis in English and noted that nearly all citrus orchards visited were ruined by HLB (Chen 1943). He described HLB in three stages:

1. "The first evident expression of the disease is that the leaves of one or few branches of the suspect suddenly turn yellow, mostly at the tip. The uninfected parts still grow normally and healthily, but chlorosis will gradually prevail to the whole tree within several months or more. The mature leaves are pale yellow, but sometimes they show chlorotic area. The roots look healthy."

2. "The diseased leaves are shedding and the new shoots begin to sprout. Most of the young leaves show chlorotic area situated between the lateral veins on each side of the midrib, or the portions between these remain green, while the green matter is lacking in veins. The diseased leaves are smaller and narrower in size, with dull faces as compared with healthy leaves. The fruit is small and abnormal in size (shape), pale yellow in color, poor in quality. The infected branches may become densely branched and stunted. The roots are rotted, but in some cases, the roots of the diseased trees are still normal."

3. "The diseased stunted branches are dying back from the tip. Following this repeated dying back of the tips, some buds are sprouting and the flowers are to put forth blossoms. Most of the roots are rotted blackly. Finally, when citrus trees are infected by this disease, it cannot be cured."

Later, Lin (1956a) provided another detailed description of HLB symptoms along with photo documentation as photographic technology became more accessible (Fig. 4):

"Citrus trees may be affected in any age. The characteristic symptoms of the disease are general yellowing of some of the nearly mature new shoots put out in summer, autumn, or early winter, dropping of the yellow leaves, and rotting of rootlets. In addition to these general symptoms in the early stage, fasciculation of branches and malformation of leaves (abnormally large or deformed in various ways) often occur on Ponkan and Chiaokan (both $C$. reticulata) and are particularly common on sweet orange. On affected sweet orange trees may also be seen shortening of internodes, resulting in bunchy growth of branches, and downward as well as upright growth of shoots."

"In a later stage, the affected tree puts out new shoots as usual but such shoots generally become chlorotic showing zinc or manganese deficiency symptoms. The midrib and lateral veins as well as the adjoining tissues of part of the older leaves turn yellow. Midrib and larger veins may also become enlarged and corky and often split on
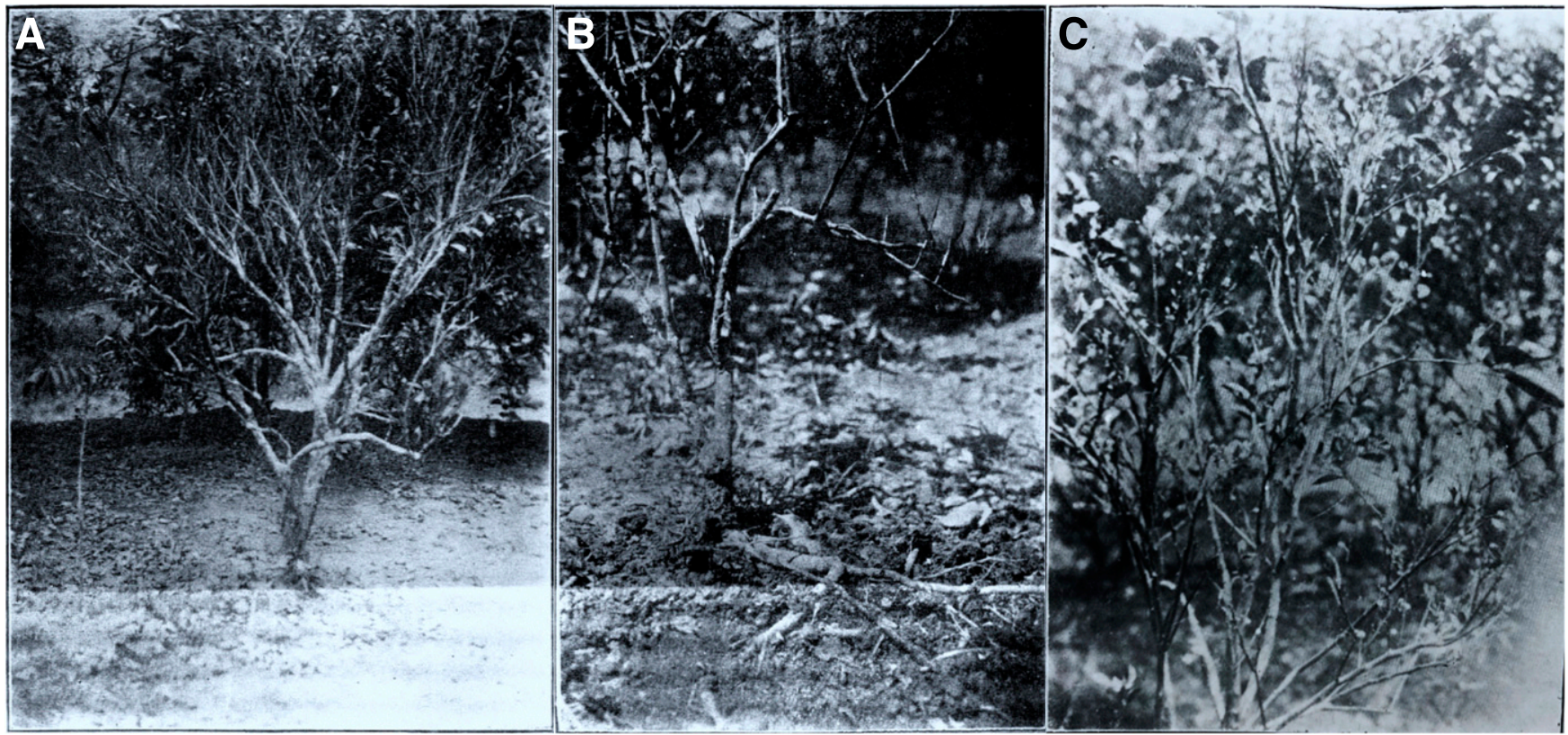

FIGURE 3

Three photographs of citrus huanglongbing published by Tu (1932). A, Sweet orange tree (Citrus sinensis Osbeck) dying from yellowing disease; B, root rot of a sweet orange tree affected by yellowing disease; and $\mathbf{C}$, untimely flowering in sweet orange affected by mottled leaf disease. 
dorsal side, showing nitrogen and boron deficiency symptoms. Affected trees blossom earlier and more heavily than usually but bear few fruits."

"On badly (severely) affected trees fruits mature earlier but do not color well and are often deformed. Defoliation and root rotting become progressively serious as the disease advances. Young trees below 7 years of age generally are killed in 1 to 2 years or sooner. Nursery trees are killed even more quickly. Older trees decline less rapidly but generally become unproductive in approximately 2 years after the first symptoms appear."

Within a span of almost 40 years (1919 to 1956) and reports from seven professionals (Reinking, Tu, Jiang, He, Huang, Chen, and Lin), the symptoms of HLB are characteristic in general yellowing of leaves. This remains true at the present (including mottling and $\mathrm{Zn}$-deficiency-like). Root problems were also common but are considered to be less HLB specific. Worth mentioning is the symptom of untimely blooming, which seemed to be quite characteristic and of value in physiopathological research. Interestingly, other than the mention of fruit not colored well (Lin 1956a), all seven early researchers did not report a so-called "red-nose" symptom of fruit. The term "red-nose" described the coloration process of a green mandarin fruit beginning at the stem end instead of the flower end. Red nose is a characteristic HLB symptom observed in Shatangju, currently the major mandarin cultivar in Guangdong (Fig. 1).

Another noticeable issue were the symptoms of "yellowing" and "mottled leaves". It appeared that yellowing was more prevalent before the 1960 s. Mottling gradually became more commonly seen since the 1970s (Zhao 2017). Even Prof. Lin acknowledged the change (Lin 1982). Current symptomatology does not identify yellowing and mottling as two distinct diseases. Yet "asymmetric blotchy mottling" is one important descriptor of HLB (Bové 2006). Because professional plant pathologists were involved, it was unlikely that the two disease symptoms were mistakenly described. Explanations for the change could be differences of citrus cultivars (e.g., from Ponkan/Chiaokan to Shatangju), culture practices (e.g., from converting paddy field to orchard to the use of better-irrigated high hill land), and unknown environmental factors. It is also possible that HLB pathogens or microorganisms changed or varied. Research in HLB etiology was highly challenging then and remains so today.

\section{ETIOLOGY - PHYSIOLOGICAL VERSUS INFECTIOUS}

Physiological etiology. With the yellowing symptom and the fact that citrus orchards were commonly converted from rice paddy fields, water logging was suspected as a primary factor responsible for HLB (Reinking 1919). However, Reinking observed that yellowing was also present in apparently well-cared-for orchards. $\mathrm{Tu}$ (1932) believed that yellowing was directly or indirectly due to "water injury" for the following reasons: (i) poor drainage was common in citrus orchards, (ii) soil around the Pearl River Delta was rather acidic and low in organic matter content, (iii) citrus trees were over interplanted with other crops that limited root development, (iv) plants were usually propagated either by air layering or using root stock that did not develop a good root system, and (v) poor insect pest management. Tree borer (Melanauster sinensis Forster) and leaf miner (Phyllocnistis citrella Stainton) insects often caused considerable defoliation and reduced tree vitality.

The "water injury" theory of HLB etiology was popular even in the 1950s. To address the issue, Lin performed a now well-known metal drum experiment (Lin 1956b). He obtained 48 1-year-old nursery trees of Chiaokan and Ponkan, divided them into three groups, and grew each tree in metal drums (Fig. 5), so that the water table of the soil could be maintained at three different levels $(13,31$, and $49 \mathrm{~cm}$ under the soil surface, respectively). After a year, both healthy and HLB trees in the $13-\mathrm{cm}$ treatment showed serious yellowing. However, the symptoms on the healthy trees were obviously different from those of HLB. Furthermore, when the water table of metal drums was lowered to $31 \mathrm{~cm}$, the healthy trees gradually recovered but not the HLB trees. He concluded that HLB of citrus was not due to water injury.

Similarly, the leaf mottling symptoms could be reminiscent of nutrient deficiency. Reinking (1919) explained mottled leaf as a physiological disorder such as lack of nutrition or disturbance of normal tree activity. Tu (1932) believed that the cause of mottling could be complicated and suspected calcium deficiency because soil in the Canton Delta (Pearl River Delta) was commonly deficient in calcium. He reported that, in soil rich in calcium, mottling was
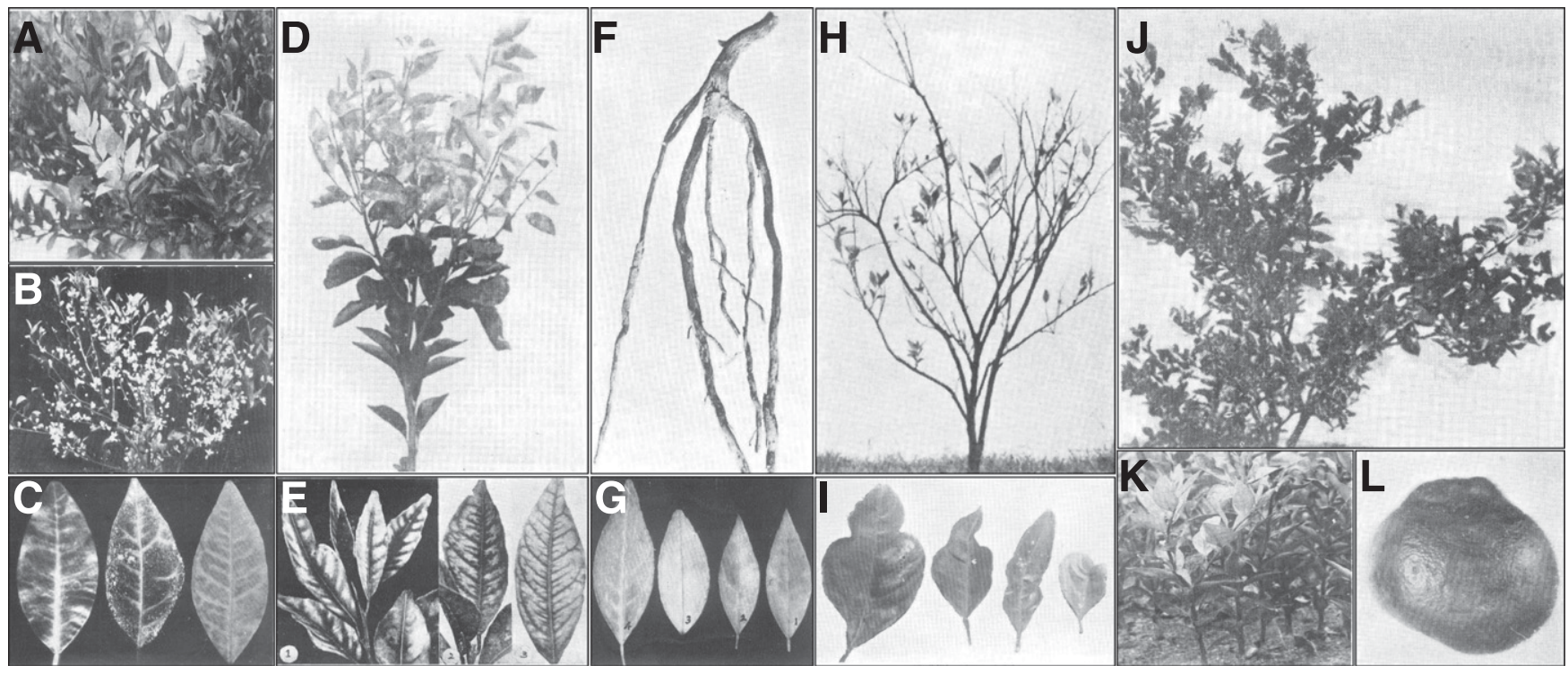

FIGURE 4

Symptoms of Huanglongbing published by Lin (1956a). A, A shoot starts to turn yellow; B, overabundance and premature flowering; C, yellowing of vein; D, yellowing of new flush; E, Zn- or Mn-deficiency-like symptoms; F, rotted roots. G, mottled leaves; H, defoliation; I, malformed leaves; J, bunchy growth of branches; $\mathbf{K}$, yellowing in seedlings; and $\mathbf{L}$, malformed fruit. 
of little concern. More toward the issue, a nutrition supplement experiment was performed (Chen 1943). Compounds such as zinc sulfate, copper sulfate, boron, calcium sulfate, ferric sulfate, potassium hydrophosphate, magnesium sulfate, and so on were used either for spraying or treating in soil. The results showed that there was no effect of these compounds on reversing HLB. Yet Prof. Chen noted one exception: leaf chlorosis returned to green within a short period in the treatment of zinc sulfate spraying. Regardless, Prof. Chen concluded that nutrition deficiency was not the cause of HLB.

Infectious etiology. The widespread occurrence of HLB and the unconvincing evidence for physiological etiology prompted the research on association of biological factors. From 1938 to 1941,
Chen (1943) performed a survey in six counties in the Chaoshan area. A representative result is shown in Figure 6. He monitored the HLB epidemic in an orchard for 2 years and found that the disease spread was in the direction of water flow of the nearby river. Physical barriers such as small hills slowed down and even blocked the disease spread. With this, he suggested that a biological factor might be involved in the HLB spread.

A Fusarium sp. was isolated from the rotted root of citrus but an inoculation experiment was not successful (He 1937). Similarly, Chen (1943) isolated a Fusarium sp. from the rotted roots but again failed to demonstrate similar symptoms with inoculation experiments. Lin and Zhu (1957) tested several species of Fusarium on HLB-affected citrus root. Some species caused severe rotting of
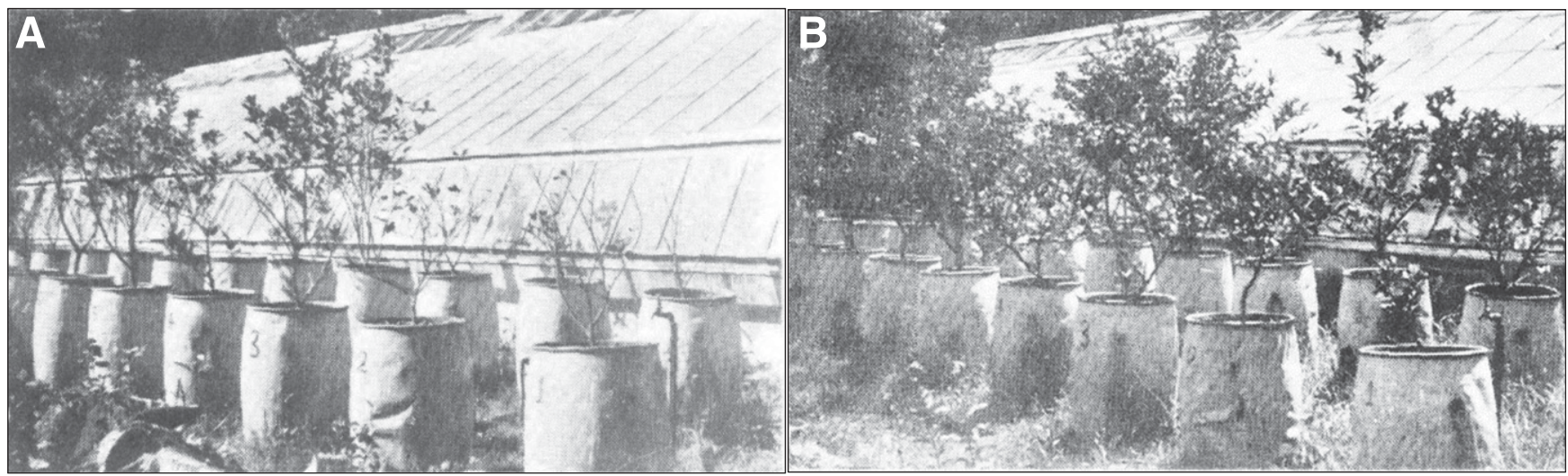

FIGURE 5

Metal drums experiment (Lin 1956b) to prove that etiology of huanglongbing (HLB) was not due to excess water. A, Drums 1 to 4 were filled and maintained with the water level $13 \mathrm{~cm}$ under the soil surface, with citrus trees showing water injury but not HLB. Drums 5 to 12 (some not in picture) were filled and maintained with water level $31 \mathrm{~cm}$ under the soil surface, with citrus trees showing no water injury. B, Water level in drums 1 to 4 as shown in A was dropped and maintained at $31 \mathrm{~cm}$ under the soil surface. Citrus trees recovered.

FIGURE 6

Two-year observation of citrus huanglongbing (HLB) development in an orchard in the Chaoshan area of Guangdong, China in the 1940s (Chen 1943). Note the spread of HLB in the direction of river water flow and the slowing of HLB when encountering small hills.

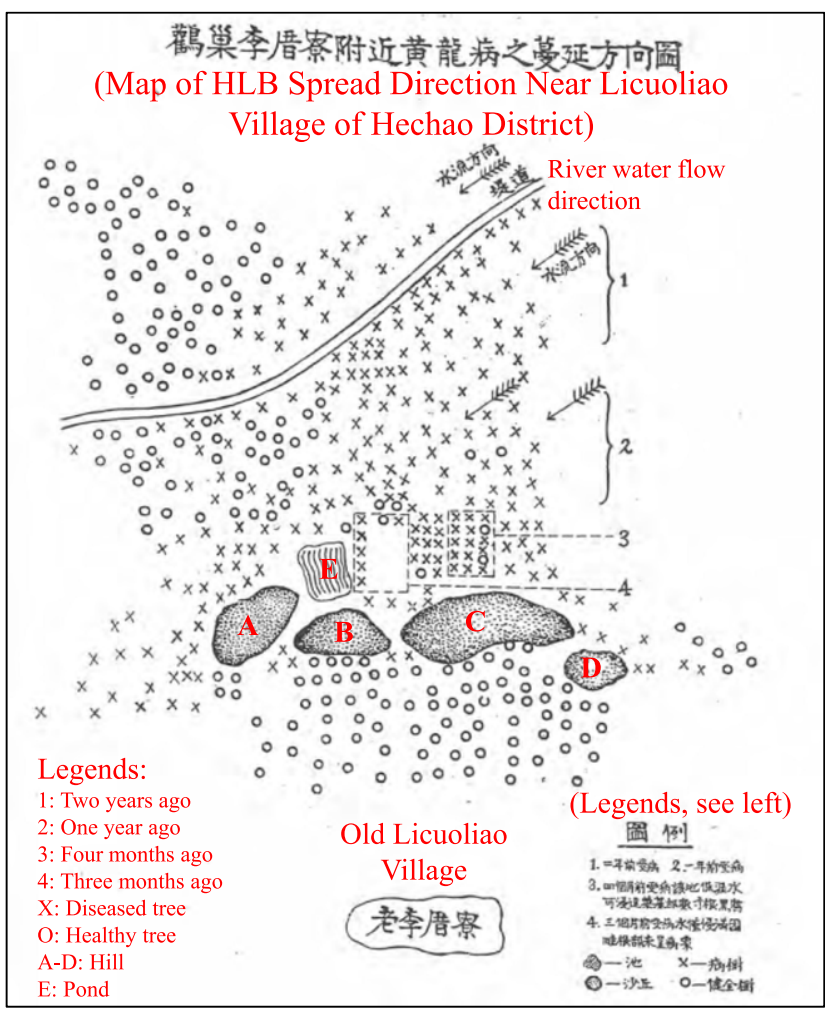


roots in both healthy and HLB trees. Other species caused rotting only of roots of HLB trees. There were still other species caused no rotting in all cases. They found that pathogenic species attacked the roots of HLB citrus trees and caused rotting, apparently in a synergistic manner. Prof. Lin also excluded the possible etiology of nematodes by examining 275 rotted rootlets from 52 affected trees microscopically. Nematodes were found on eight rotted rootlets of five trees. Furthermore, the symptoms of yellow shoot are distinctly different from those of the type of decline of citrus caused by nematode infestation (Lin 1956b).

A hypothesis of virus etiology for HLB was raised (Chen 1943). Experiments were performed through grafting (mostly top-working) scions on healthy trees. Scions from a healthy tree resulted in no HLB symptoms. Yet scions from an HLB tree led to HLB symptoms. Furthermore, grafting with a healthy-looking scion from an HLB tree also led to the development of HLB symptoms. An interesting bridge-grafting experiment is shown in Figure 7. In this case, an HLB Chiaokan $(C$. reticulata) tree was bridge grafted with a healthy Chiaokan on a sour tangerine rootstock. Five months later, the Chiaokan shoot showed HLB symptoms but not the sour tangerine shoot. Results from grafting experiments suggested that citrus HLB or tip-chlorosis might be due to a virus.

Prof. Lin further consolidated the virus etiology hypothesis through extensive experiments. In the first experiment (Table 2), starting in 1950, 29 1-year-old trees of Ponkan and 26 trees of Chiaokan were inoculated by grafting. After approximately 8 months, $41.5 \%$ of inoculated Ponkan trees and $50.0 \%$ of the inoculated Chiaokan trees showed obvious yellow shoot symptoms, significantly different from the controls. Follow-up examinations in 1952 showed an increase of infection rates (Table 2).

In the second experiment, starting in 1952, 127 1-year-old trees of Chiaokan and 93 similar trees of Ponkan were inoculated through grafting with buds from HLB trees (Table 3). After 9 months, for the trees with live grafted buds, $48.3 \%$ of the 58 inoculated Chiaokan trees and $57.9 \%$ of the 57 inoculated Ponkan trees were affected and showed typical yellow shoot symptoms. For the control, 105 Chiaokan trees and 112 Ponkan trees remained healthy. For the buffer trees, 58 Chiaokan and 73 Ponkan also remained healthy. Among the trees on which inoculated buds that failed, only a small percentage of infection occurred. The percentage of infection in trees with two buds survived was about twice of those trees with only one bud survived. In 1953, reinoculation was made on both Chiaokan and Ponkan that had been inoculated in 1952 but were apparently not infected. The results obtained in the following year were in agreement with those of the previous year, except that small percentages of the control and buffer trees were also infected. The percentage of infection of the inoculated trees was consistently higher than that of those in the previous year. The results of these

FIGURE 7

Diagram of bridge-grafting experiment to demonstrate transmission of Huanglongbing (HLB) pathogen by Prof. C. P. Chen (Chen 1943). A, A

3-year-old HLB-affected Chiaokan (Citrus reticulata) tree; B, 2-year-old Chiaokan showing HLB symptoms after 4 months of bridge-grafting; and

C, rootstock (sour tangerine) of Chiaokan showing no HLB symptoms.

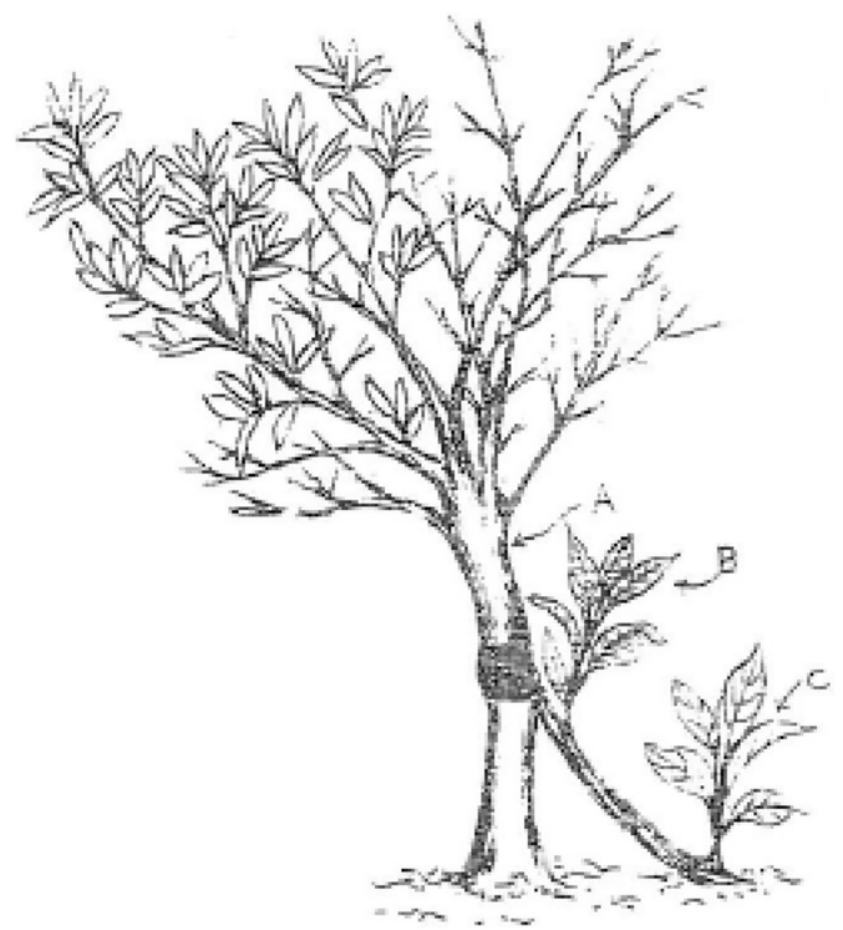

TABLE 2

Results of the first grafting experiment to prove infectivity of citrus Huanglongbing (HLB) starting in 1950 (Lin $1956 \mathrm{~b}$ )

\begin{tabular}{|c|c|c|c|c|}
\hline \multirow[b]{3}{*}{ Examination time } & \multicolumn{4}{|c|}{ Citrus reticulata cultivar, treatment, infection rate (\%) } \\
\hline & \multicolumn{2}{|c|}{ Ponkan } & \multicolumn{2}{|c|}{ Chiaokan } \\
\hline & Grafted & Control & Grafted & Control \\
\hline December 1950 & 41.5 & 3.2 & 50.0 & 0.0 \\
\hline January 1952 & 59.2 & 18.7 & 56.0 & 17.6 \\
\hline
\end{tabular}


inoculation experiments were interpreted to prove that a virus was the primary causal agent of HLB. Also, through a grafting experiment, Prof. Lin further demonstrated that the HLB "virus" moved both upward and downward from the point of inoculation (Lin 1963).

\section{HLB CONTROL-SUCCESS AND FAILURE}

Through the years, there were numerous trials or experiments from growers and researchers to control HLB. Some were successful and some failed but no detailed documentation of these analyses exist. Jiang et al. (1935b) suggested rotation with rice or other crops for several years before replanting citrus. Other management efforts focused on finding and using resistant cultivars. According the Prof. Lin, nearly all of the species and varieties of citrus grown in the affected area were susceptible (Lin 1956a). However, he gave a list of citrus cultivars showing variations in susceptibility from high to low: Ponkan, Chiaokan, Chachihkan, Lukan, Tungkan (all C. reticulate), various varieties of sweet orange (C. sinensis), Hungninmeng (hybrid of C. lemon and $C$. reticulata), Nienchu (C. reticularta), Shangmayu (C. gradnis), and Shihchichu (C. mitis). Indeed, Prof. Chen (1943) reported that a grower in Chaozhou successfully grafted Chiaokan and Ponkan scions on pomelo tree stocks and produced good quality and quantity of fruit. However, a recent study in Guangdong showed that pomelo was highly susceptible to HLB (Deng et al. 2008).

With the infectious virus etiology, Prof. Lin first pointed out that a quarantine measure had to be taken in citrus production area (Lin 1956b, 1957a,b). In a later publication (Lin 1963), he presented four perspectives on HLB control.

1. Removal of diseased trees. An experiment was performed in the Rouping citrus research institute in 1956 on a 4-year-old Chiaokan orchard. The treatment plot had 229 trees and the control plot had 197 trees. An HLB tree was diagnosed by symptomatology. At the beginning, there were 11 HLB trees in the treatment plot and 12 HLB trees in the control plot. The 11 HLB trees in the treatment plot were removed but the 12 HLB trees in the control plot were kept. In August 1958, eight HLB trees were found in the treatment plot and were removed. At the same time, 19 additional HLB trees were diagnosed in the control plot, and kept. The experiment was concluded in March 1961 when there were 67 HLB trees in the treatment plot with $[67 /(229-11-8)]=31.9 \%$ infection rate. However, an additional 112 HLB trees were diagnosed in the control plot, resulting in an infection rate of $[(12+19+112) / 197]=$
72.6\%. Clearly, removal of infected trees helped to slow down HLB spread.

2. Insect control. An insecticide spraying experiment was performed in the Chaozhou citrus research institute in 1956. No specific insect was targeted because the vector of the HLB pathogen was unknown. Aphids, red mites, leaf hoppers, whiteflies, and psylla were collected together for experiments. Three experimental plots were set up, each plot had 50 groups, and each group had a graft-infected tree as a center surrounded with four 4-year-old and four 2-year-old Chiaokan trees. Insects were placed in the center trees. Insect growth was monitored. Insecticide spray was applied to the surrounding trees before insects start to spread out. For the control plot, no spray was applied unless severe insect damage occurred. It was observed that trees in treatment plots showed significant reduction of HLB and grew more vigorously.

3. Sterilization of scions. Young shoots of symptomatic tree were taken and treated with hot water and saturated hot air. Buds were taken and grafted on 1-year-old Chiaokan stock. Seven months later, all no-heat $=$ or low-heat-treated trees showed HLB symptoms yet high-temperature-treated trees showed no HLB symptoms.

4. Cultural management. Surveys in citrus orchards managed by experienced growers observed that all had HLB trees. Therefore, although better cultural practice are generally important in overall disease management, they were not enough to prevent HLB development if quarantine procedures were not taken.

A systematic heat treatment experiment had shown great promise in managing HLB (Lin and Zheng 1964). Hot water treatment was found to kill healthy budwood tissue. However, the use of water-vapor-saturated hot air in the range of 48 to $58^{\circ} \mathrm{C}$ for $4 \mathrm{~h}$ to $10 \mathrm{~min}$ resolved the problem. Heat treatment parameters were further fine-tuned using temperatures of 48 to $58^{\circ} \mathrm{C}$ for 45 to $65 \mathrm{~min}$ and $51^{\circ} \mathrm{C}$ for 30 to $55 \mathrm{~min}$ (Lin and Luo 1965). As the mottling type of HLB became more prevalent, Luo et al. (1981) tested the hot air treatment for this HLB type. They found that treatments of $48^{\circ} \mathrm{C}$ for 50 to $60 \mathrm{~min}$ or $50^{\circ} \mathrm{C}$ for $50 \mathrm{~min}$ were effective in HLB control. Later, a procedure of intermittent hot air treatment with 47 to $50^{\circ} \mathrm{C}$ for 6 to $12 \mathrm{~min}$ a day for three consecutive days was developed (Luo 1983). The heat treatment procedure was originally used to obtain HLB-free scions from affected citrus trees to meet the need of citrus orchard establishment. Alternatively and later on, HLB-free mother tree systems were established through shoot-tip grafting technology and used as the source of scions.

TABLE 3

Results of the second grafting experiment to prove infectivity of citrus Huanglongbing starting in 1952 (Lin $1956 \mathrm{~b}$ )

\begin{tabular}{|c|c|c|c|c|c|c|c|c|}
\hline \multirow{3}{*}{ Trees } & \multicolumn{8}{|c|}{ Citrus reticulata cultivar, year, infection rate ${ }^{a}$} \\
\hline & \multicolumn{4}{|c|}{ Chiaokan } & \multicolumn{4}{|c|}{ Ponkan } \\
\hline & \multicolumn{2}{|c|}{1952} & \multicolumn{2}{|c|}{1953} & \multicolumn{2}{|c|}{1952} & \multicolumn{2}{|c|}{1953} \\
\hline Control & 105 & 0 & 105 & 6.60 & 112 & 0 & 112 & 0 \\
\hline Buffer & 58 & 0 & 58 & 31.00 & 73 & 0 & 73 & 5.40 \\
\hline No bud survived & 69 & 7.20 & 22 & 63.60 & 36 & 22.20 & 1 & 0 \\
\hline Single bud survived & 31 & 32.20 & 36 & 75.00 & 36 & 41.70 & 4 & 75.00 \\
\hline Two buds survived & 27 & 66.60 & 36 & 88.80 & 21 & 85.70 & 46 & 84.80 \\
\hline Sum of all buds survived & 58 & 48.30 & 72 & 82.00 & 57 & 57.90 & 50 & 84.00 \\
\hline Sum of all grafted & 127 & 26.00 & 94 & 77.60 & 93 & 44.10 & 51 & 82.30 \\
\hline
\end{tabular}


The proposal of Prof. Lin for HLB control was later summarized in three key measures: (i) use of clean nursery stock with regional quarantine, (ii) scouting and removal of diseased trees immediately, and (iii) control of insect vectors.

A good example showing the effectiveness of the three key measures for HLB control is the citrus management story of Yangcun Citrus State Farm (YCSF). YCSF was established in 1951 and started to plant citrus in 1953. YCSF grew from 2.3 ha $(38 \mathrm{Mu})$ in 1953 to $1,529 \mathrm{ha}(22,935 \mathrm{Mu})$ in 1961 . Citrus seedlings were mainly from a state-run citrus experiment station in the Chaoshan area, with the criteria of having no HLB symptoms. Initially, HLB trees were rarely found. A survey in 1959 revealed only five suspected HLB trees. From 1960 to 1973, sporadic HLB trees, including local groves with $90 \%$ incidence, were found. Removal of HLB trees was proposed by Prof. Lin but was ignored due to the lack of understanding of the disease by the YCSF administration. Instead, citrus management focused on highquality cultivars, vigorous nursery stocks, and better cultivation practices.

From 1974 onward, ACP became more commonly found and the number of HLB trees increased, showing signs of disease outbreak. In 1978, approximately 20 to $50 \%$ of trees were affected by HLB. In winter 1981, nearly 960,000 trees in production along with nearly 200,000 young trees just put out for production were removed due to HLB. Citrus production rapidly decreased from 215,000 tons in 1977 to 53,000 tons in 1982 .

As the HLB outbreak continued to take its toll on citrus production, YCSF learned the lesson, started to prioritize HLB control, and actively engaged in a rebuilding process. From 1979 to 1993 , HLB technical training classes were held at least twice a year and mandated for each employee. Several strategies were implemented for orchard recovery. (i) Area-wide HLB survey and replanting was performed (e.g., orchards with an HLB rate over 20 to $30 \%$ were demolished and replanted after 1 to 2 years. (ii) ACP control was a top priority. Insecticides were sprayed one to two time during the flushes in spring, summer, and fall, systematically and uniformly throughout the farm (iii) HLB-free nursery stocks were developed and used. Rootstock seed were treated for $50 \mathrm{~min}$ in hot water $\left(55\right.$ to $\left.56^{\circ} \mathrm{C}\right)$ along with $3 \mathrm{~h}$ of treatment with tetracycline $(1,000 \mathrm{U} / \mathrm{ml})$. Scions had to be from HLB-free mother trees. Following these measures, the incidence of HLB declined from $3.9 \%$ before 1978 to $0.3 \%$ in 1992 . The citrus acreage returned back to 2,000 ha in 1991 (Zhao 2017).

Unfortunately, after 1993, following the structural reform for development of state farms in China, the management system of YCSF was privatized. To save costs, they reduced the use of organophosphates, which were primarily used for psyllid control. The use of organophosphates declined14.2 to $68.4 \%$ from 1992 to 1993 . This resulted in an outbreak of psyllids and HLB. Incidence of HLB was increased to $15.57 \%$. In 1996, the YCSF was operated under the system of "Transfer of property rights". As a result, it became more difficult to uniformly implement the three key measures, resulting in rapid spread of HLB. In total, 1.89 million HLB-affected trees were removed from 1994 through 1999 and $<300$ ha of cultivation area survived in 2002.

The province-wide HLB situation in Guangdong is also worth mentioning. Starting in the mid-1990s, major citrus production in Guangdong moved to the inland hillock mountainous north and west regions (Fig. 1). A highly marketable mandarin cultivar, Shatangju (C. reticulata), originating from Sihui City (Fig. 1), was grown. Most of the Shatangju growing areas were newly developed and free of the HLB pathogen. The acreage of citrus planting quickly reached approximately 140,000 ha by 2010 . Ironically and unfortunately, HLB control was not in the pest management program. HLB-infected nursery stocks spread widely. As a result, HLB began to reemerge in mid 2000s. As of now, citrus production in Guangdong is facing another downward turn.

\section{EMERGING LIBERIBACTER ETIOLOGY}

In the search for viruses and based on experiments using index plants, HLB was considered to be Tristeza disease (Chen and Mei 1965). However, later research pointed out that HLB was different from Tristeza disease in its response to different rootstocks. For example, Poncitrus rootstock was resistant to Tristeza but not HLB (Zhao et al. 1979). The continuous failure of in vitro isolation of the HLB pathogen prompted the pathogen search in planta. The availability of electron microscopy empowered the search for microorganisms in HLB tissues. A virus of 110 to 130 by 25,000 to $30,000 \AA$ was observed in an HLB tree (Shanghai Institute of Biochemistry of Chinese Academy of Sciences 1973). However, no further characterization followed. Two years later, tetracycline was found to suppress the symptoms of HLB (Guangxi Citrus Huanglongbing Research Group 1976), suggesting the bacterial etiology.

The association of HLB (citrus greening disease) with bacteria was first observed in 1970 in the phloem of affected sweet orange leaves in France (Laflèche and Bové 1970). Along with the discovery of mycoplasma-like organisms (MLO) associated with several plant diseases, particularly yellowing diseases, the organism was thought of as an MLO. By analogy with MLO, these organisms have been called bacterium-like organisms; they have also been inappropriately called rickettsia-like organisms (RLO). The organisms were renamed phytoplasmas in 1994, at the 10th Congress of the International Organization for Mycoplasmology. Soon, however, it was realized that the HLB agent should be a walled bacterium because of the 25-nm-thick (rather than 7 to $10 \mathrm{~nm}$ ) envelope (Saglio et al. 1971).

Based on the results of 3 years of experiments, Ke et al. (1979) reported the presence of RLO in five samples of HLB-affected citrus trees ( $C$. limon, $C$. sinensis, and $C$. reticulata) showing typical leaf mottling symptoms. Two of the leaf mottling samples also showed viruses with a diameter of 10 to $13 \mathrm{~nm}$, and one of them tested positive for Tristeza virus. Sizes of RLO were measured as 50 to 600 by 170 to $1,600 \mathrm{~nm}$. The outside wall of the RLO consisted of three layers, with the middle being lighter and having a thickness of 17 to $33 \mathrm{~nm}$. Follow-up research included transmission through dodder (Cuscuta campestris Yunck) and enrichment of the RLO in periwinkle plants (Ke et al. 1986).

Chen et al. (1979) reported the observation of MLO in phloem tissues of leaf samples collected in two locations of Guangdong, including one in Puning (Chaoshan area) in September 1978. The pleomorphic MLO was 60 to $79 \mathrm{~nm}$ in size, with a bilaminar unit membrane having a thickness of $20 \mathrm{~nm}$. Filamentous virus particles were also observed. A year later, the same authors reported that injection of tetracycline hydrochloride into diseased trees diminished the MLO titer and reduced the HLB symptoms (Chen et al. 1980). Interestingly, they also mentioned that treatment with penicillin reduced the yellowing symptoms. Another observation was of a mixed infection of MLO and a thread-shaped virus reported previously, raising the issue of the etiological role of the two organisms in HLB.

Based on characteristics in the $16 \mathrm{~S}$ ribosomal RNA (rRNA) gene sequence, an official name for the HLB-associated bacterium originally collected from India was proposed, initially ' $\mathrm{Ca}$. L. asiaticum' and later ' $\mathrm{Ca}$. L. asiaticus', from Dr. Jose Bové's laboratory in France (Jagoueix et al. 1994). Oligosequence OI1 was designated as the signature sequence for ' $\mathrm{Ca}$. L. asiaticus'. Primer set OI1-OI2c was used as a standard for polymerase chain reaction (PCR) detection. Two years later, ' $\mathrm{Ca}$. L. asiaticus' was confirmed to be associated with HLB in Guangdong (Deng and Tang 1996) and Fujian (Tian et al. 1996).

\section{'CA. L. ASIATICUS' CHARACTERIZATION AND DETECTION}

The establishment of ' $\mathrm{Ca}$. L. asiaticus' association with HLB immediately impacted the field of HLB research and management. 
PCR with primer set OI1-OI2c and the derivative primer set HLBas$\mathrm{HLBr}$ (Li et al. 2006) became a standard used as a confirmatory tool to supplement and to increase the accuracy of HLB diagnoses. In addition to primer sets from the $16 \mathrm{~S}$ rRNA gene, Dr. Bové's lab also released two other primer sets, one from a $\beta$-operon of ribosomal protein gene (rplA/J) (Planet et al. 1995; Villechanoux et al. 1992, 1993) and one from an outer membrane protein gene (omp) (Bastianel et al.2005). These genomic loci were empirically identified through random DNA fragment analyses. The three primer sets were used to evaluate strains of ' $\mathrm{Ca}$. L. asiaticus' in pummelo samples from six different locations in Guangdong (Deng et al. 2008). All pummelo strains were highly homogeneous. Analyses of single-nucleotide polymorphisms in the omp locus showed a low level of diversity among strains from different countries or regions, suggesting a need to explore more robust genomic loci for ' $\mathrm{Ca}$. L. asiaticus' population diversity studies.

The whole-genome sequence of ' $\mathrm{Ca}$. L. asiaticus' (Duan et al. 2009) provided access to all genomic loci for the bacterial biology and population diversity research. Locus CLIBASIA_01645 containing small tandem repeats was found and selected to design primer set LapGP-1f/LapGP-1r (Chen et al. 2010). Analyses of tandem repeat numbers (TRN) showed that the Guangdong population consisted predominately of strains with TRN $=7$ at a frequency of $47.6 \%$. The Florida population consisted predominately of strains with TRN $=5$ at a frequency of $84.4 \%$. These demonstrated the difference in ' $\mathrm{Ca}$. L. asiaticus' populations between Guangdong and Florida. In a follow-up study, 224 ' $\mathrm{Ca}$. L. asiaticus' samples from southern China were analyzed and significant differences were observed between the ' $C a$. L. asiaticus' population from Guangdong Province and those from the other provinces in China (Ma et al. 2014).
Prophage locus CLIBASIA_05610, encoding a prophage terminase large subunit, was also found to be useful to evaluate ' $C a$. L. asiaticus' diversity (Liu et al. 2011). Primer set 766f/766r derived from this locus was used to assess the variation between the ' $\mathrm{Ca}$. L. asiaticus' populations from two geographically distinct provinces (Guangdong and Yunnan). The frequency of 766f/766r was $15.8 \%$ in Guangdong and $97.4 \%$ in Yunnan, revealing variation of ' $\mathrm{Ca}$. L. asiaticus' populations inside China. Analyses with other genomic regions such as CLIBASIA_05640 and CLIBASIA_05650 also confirmed the variation (Wang et al. 2012). Putting together the loci of CLIBASIA_01645 and CLIBASIA_05610, a double local (DL) analysis was performed using 301 ' $\mathrm{Ca}$. L. asiaticus' strains from Brazil, China, and the United States (Deng et al. 2014). ' $C a$. L. asiaticus' strains were clustered mostly according to geographical origin. DL genotype 1 included $97 \%$ of the Chinese strains, DL genotype 2 included all Brazilian strains, and DL genotype 3 included $93 \%$ of the U.S. strains. Meanwhile, the DL analysis successfully revealed intercontinental overlaps of ' $\mathrm{Ca}$. L. asiaticus' populations. Two primer sets, CT3f/CT3r, specific to Chinese ' $\mathrm{Ca}$. L. asiaticus' strains, and FC3f/FC3r, specific to the majority of Florida ' $\mathrm{Ca}$. L. asiaticus' strains, were developed and used to evaluate ' $C a$. L. asiaticus' strains in California (Zheng et al. 2017).

Strain Psy62 used for the ' $C a$. L. asiaticus' whole-genome sequencing was collected from an ACP with very high ' $\mathrm{Ca}$. L. asiaticus' titer in Florida (Duan et al. 2009). However, collection of ' $C a$. L. asiaticus' from ACP could be difficult due to the low infection rate. In contrast, ' $\mathrm{Ca}$. L. asiaticus' samples were more easily collected from symptomatic citrus tissue. In addition, more and more studies showed that ' $\mathrm{Ca}$. L. asiaticus' strains in China were different from those in Florida. All these necessitated a procedure to obtain the whole-genome sequence of ' $\mathrm{Ca}$. L. asiaticus'

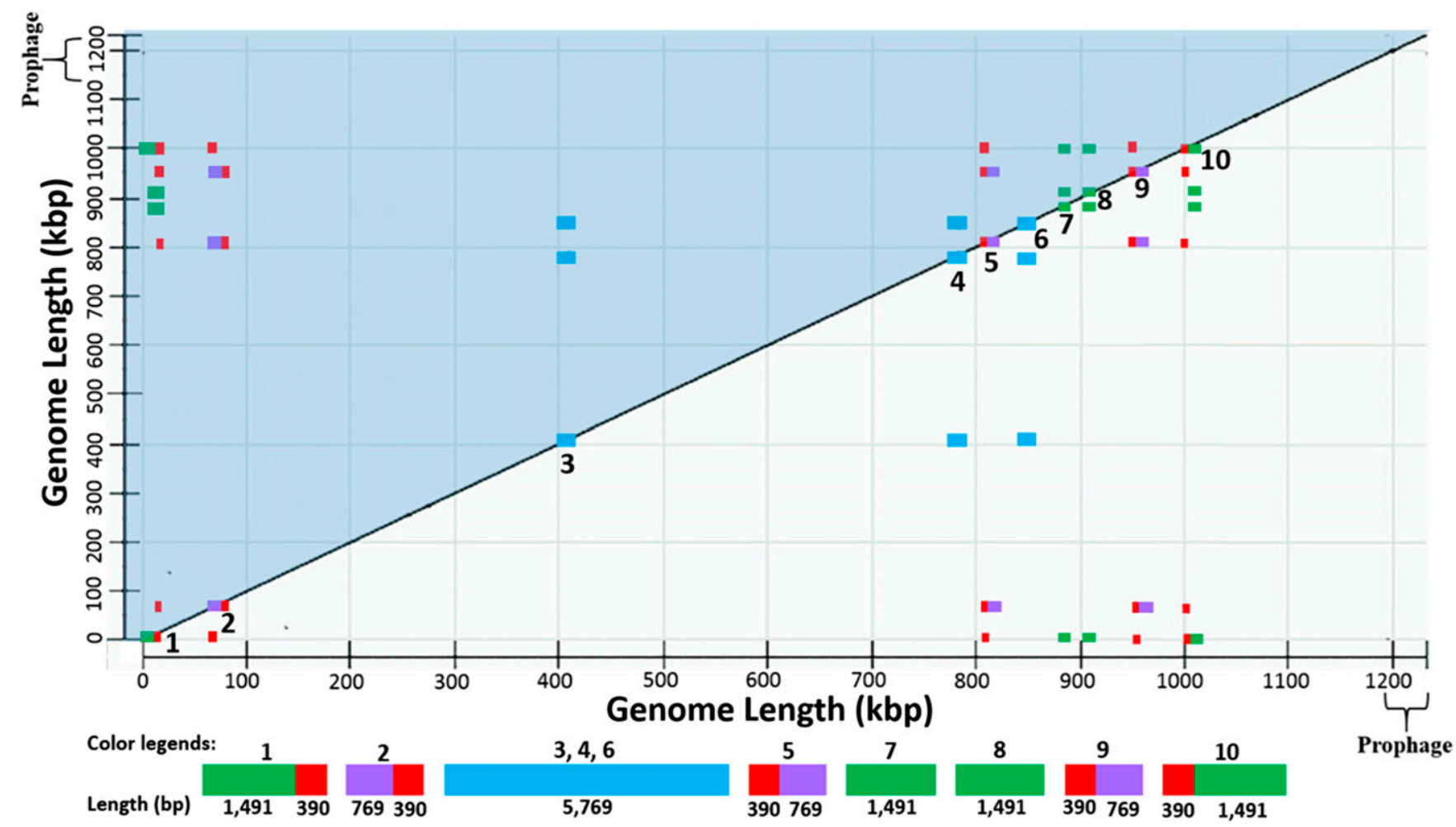

FIGURE 8

Visualization of repeat regions in the genome sequence of 'Candidatus Liberibacter asiaticus' strain A4 (CP010804) by Zheng et al. (2016b). The upper-left diagonal (in blue shadow) shares the same information as the bottom-right diagonal. Examination of one diagonal (e.g., the bottom-right) reveals 10 repeat regions on the diagonal line labeled with numbers accordingly. The repeat sequences are marked with the same shading. The red color sequence (390 bp) has the highest copy number of five (region 1, 2, 5, 9, and 10). Regions 3, 4, and 6 are the rrn operon in blue. 
from citrus samples in China. Zheng et al. (2014) established a procedure, called enrichment, enlargement, and next generation sequencing (NGS) analysis (EENA), and obtained a draft genome sequence of ' $\mathrm{Ca}$. L. asiaticus' strain A4 (CP010804.1) originating from a mandarin tree in Sihui City of Guangdong. The procedure involved the transmission of ' $\mathrm{Ca}$. L. asiaticus' from citrus to periwinkle via dodder, enrichment of bacterial DNA, amplification of enriched DNA, and sequencing using Illumina MiSeq. Following the same procedure with modifications, Wu et al. (2015) obtained a whole-genome sequence of a ' $\mathrm{Ca}$. L. asiaticus' strain in ACP from YCSF. The use of EENA and its modified procedure has led to the successful acquisition of seven additional whole-genome sequences of ' $\mathrm{Ca}$. L. asiaticus' strains from China and the United States. The sequences have been deposited in GenBank.

The information extracted from whole-genome sequences was quickly used to improve ' $\mathrm{Ca}$. L. asiaticus' detection. A five-copy $n r d B$ gene coding for ribonucleotide reductase $\beta$-subunit, a key enzyme involved in DNA precursor synthesis and DNA repair by converting ribonucleotides to deoxyribonucleotides, was found through whole-genome sequence comparison (Fig. 8) (Zheng et al. 2016b). A primer-probe set, RNRf/RNRp/RNRr, was designed. Compared with the standard primer-probe set, HLBas/HLBp/ HLBar, based on the 16S rRNA gene sequence, which had three genome copies, the RNRf/RNRp/RNRf method increased the sensitivity of ' $\mathrm{C} a$. L. asiaticus' detection by three times (Zheng et al. $2016 \mathrm{~b})$. The five-copy property of $n r d B$ gene was recently used to develop a duplex droplet digital PCR methodology (Selvaraj et al. 2018).

Worthy of mention is the development of the read-mapping technique based on NGS data (Zheng et al. 2017). Short reads of NGS output were used to map to a known ' $\mathrm{Ca}$. L. asiaticus' sequence. The mapping results or profiles were used to differentiate two closely related ' $\mathrm{Ca}$. L. asiaticus' strains from Hacienda Heights and San Gabriel in California. The former had a type 2 prophage, whereas the later had a type 1 prophage (Zheng et al. 2017). The presence of different prophages suggests that the two California ' $\mathrm{Ca}$. L. asiaticus' strains could have been introduced from different sources.

Another significant contribution of whole-genome sequence research is the discovery of new biological traits of ' $\mathrm{Ca}$. L. asiaticus'. Wang et al. (2013) discovered two miniature inverted-repeat transposable elements, autonomous transposons devoid of the transposase gene tps. Zheng et al. (2016a) performed in silico analyses and identified a clustered regularly interspaced short palindromic repeat (CRISPR)/CRISPR-associated protein gene system. Recently, Zheng et al. (2018) detected a new type 3 prophage, P-JXGC-3, that encoded a restriction-modification system ( $h s d R, h s d S, h s d M 1$, and $h s d M 2$ ) in a ' $\mathrm{Ca}$. L. asiaticus' strain from Jiangxi Province, neighboring Guangdong. It is expected that many more biological details of ' $\mathrm{Ca}$. L. asiaticus' will be revealed as NGS-based studies move forward in the near future.

\section{SUMMARY THOUGHTS}

HLB is a historical problem on citrus production in southern China. Research in the disease has been particularly challenging, mainly related to the complexity of the disease etiology and ecology and the lack of effective technology for research. Looking into the records of early HLB studies, one obvious issue is the yellowing and mottling symptom descriptions. Were they the same or different diseases? Before the 1970s, yellowing was more prevalent. However, since the 1970s, mottling has become more dominant. As of today, yellowing and mottling are together considered to be key HLB symptoms. There could be many explanations for the ratio changes between yellowing and mottling in HLB descriptions, as discussed earlier. All require further research evidence. In the context of etiology, the quick subsiding of ' $\mathrm{Ca}$. L. americanus' in
Brazil could be a reminder that the HLB pathogen (and related microorganisms) could vary over time. Regardless, the three key measures remain applicable for consideration of HLB management (Lin 1982).

With the current nonculturable status of ' $\mathrm{Ca}$. L. asiaticus', NGS has been a powerful tool for the bacterial characterization and population diversity research. In fact, even when ' $C a$. L. asiaticus' is successfully cultured in vitro in the future, genomic research of the bacterium will still be highly significant. One obvious and immediate contribution of ' $\mathrm{Ca}$. L. asiaticus' whole-genome or HLB metagenome sequencing is the use for improvement of HLB diagnosis in both sensitivity and accuracy. An example is the discovery and utilization of high-copy-number genes to improve PCR detection of ' $C a$. L. asiaticus' (Zheng et al. 2016b). Sequencebased research has also revealed that there could be at least two different ' $\mathrm{C} a$. L. asiaticus' populations in China. However, there has not been analysis of their relevance to virulence and pathogenicity. The impact of strain diversity in HLB epidemiology remains to be studied.

For HLB management, it should be noted that symptomatology remains useful and critical for disease diagnoses. Symptoms are direct reflections of pathological processes. Thus far, symptom analysis of HLB has been based on visible light, either in writing or in photography. Images acquired with hyperspectral and machinelearning technologies are now available. Symptom analyses based on this new technologies are expected to significantly advance HLB diagnostics. Finally, it is clear that HLB management is hampered by insufficient biological knowledge. However, there is also a sociological side to HLB control. The boom and bust of citrus production in the YCSF case showed that (i) HLB education and extension is very important and (ii) there is much to learn about how to use available resources in coordination with the social changes required to achieve successful HLB control.

\section{ACKNOWLEDGMENTS}

We are indebted to Dr. Lin Kong-Hsiang (林孔湘) and a group of plant pathologists who dedicated their careers to HLB research and control in southern China from the 1950s to 1990s. Many of them have few or no publications in English and are unknown to the HLB research community today. However, they deserve to be acknowledged. They are: Ke Chong (柯冲), Zhao Xueyuan (赵学源), Luo Xuehai (洛学海), Luo Zhida (罗志达), Tang Weiwen (唐伟文), and more who are not named here due to space limitations. Mention of trade names or commercial products in this publication is solely for the purpose of providing specific information and does not imply recommendation or endorsement by the U.S. Department of Agriculture. USDA is an equal opportunity provider and employer.

\section{LITERATURE CITED}

Arratia-Castro, A. A., Santos-Cervantes, M. E., Fernández-Herrera, E., Chávez-Medina, J. A., Flores-Zamora, G. L., Camacho-Beltrán, E., Méndez-Lozano, J., and Leyva-López, N. E. 2014. Occurrence of 'Candidatus phytoplasma asteris' in citrus showing Huanglongbing symptoms in Mexico. Crop Prot. 62:144-151.

Bastianel, C., Garniersemancik, M., Renaudin, J., Bové, J. M., and Eveillard, S. 2005. Diversity of "Candidatus Liberibacter asiaticus" based on the omp gene sequence. Appl. Environ. Microbiol. 71:6473-6478.

Bové, J. M. 2006. Huanglongbing: A destructive, newly-emerging, century-old disease of citrus. J. Plant Pathol. 88:7-37.

Chen, C. P. 1943. A report of a study on yellow shoot disease of citrus in Chaoshan. New Agric. Q. Bull. 3:142-177.

Chen, J., Deng, X., Civerolo, E. L., Lee, R. F., Jones, J. B., Zhou, C., Hartung, J. S., Manjunath, K. L., and Brlansky, R. H. 2011. "Candidatus Liberibacter species": Without Koch's postulates completed, can the bacterium be considered as the causal agent of citrus Huanglongbing (yellow shoot disease)? Acta Phytopathol. Sin. 41:113-117. 
Chen, J., Deng, X., Sun, X., Jones, D., Irey, M., and Civgerolo, E. 2010. Guangdong and Florida populations of 'Candidatus Liberibacter asiaticus' distinguished by a genomic locus with short tandem repeats. Phytopathology 100:567-572.

Chen, J., Pu, X., Deng, X., Liu, S., Li, H., and Civerolo, E. 2009. A phytoplasma related to 'Candidatus phytoplasma asteris' detected in citrus showing Huanglongbing (yellow shoot disease) symptoms in Guangdong, P. R. China. Phytopathology 99:236-242.

Chen, T.-Y., Shen, C.-Y., Kung, T.-H., Chen, N.-W., and Tai, Y.-M. 1980. The pathogens of citrus yellow shoot disease and their reaction towards antibiotics. Acta Biochim. Biophys. Sin. (Shanghai) 12:143-146.

Chen, T. Y., Shen, J. Y., Tao, S. Z., Gong, Z. X., Chen, N. R., and Dai, Y. M. 1979. Studies on the pathogens of Huanglongbing (Citrus yellow shoot disease) III. Mycoplasma-like organisms associated with Huanglongbing in Guangdong. Acta Biochim. Biophys. Sin. (Shanghai) 11:191-192.

Chen, Y. H., and Mei, J. H. 1965. A preliminary study of the citrus yellow shoot virus. Acta Phytophylac. Sin. 4:361-363.

Coletta-Filho, H. D., Targon, M. L. P. N., Takita, M. A., De Negri, J. D., Pompeu, J., Jr., and Machado, M. A. 2004. First report of the causal agent of Huanglongbing ("Candidatus Liberibacter asiaticus") in Brazil. Plant Dis. $88: 1382$

Crawford, D. L. 1919. The jumping plant lice of the Palaeotropics and the South Pacific Islands. Philipp. J. Sci. 15:139-207.

Das, A. K., Nerkar, S., Thakre, N., and Kumar, A. 2016. First report of 'Candidatus phytoplasma trifolii' (16srVI group) in Nagpur mandarin (Citrus reticulata) showing Huanglongbing symptoms in central India. New Dis. Rep. 34:15.

Deng, X., Chen, J., Feng, Z., Shan, Z., Guo, H., Zhu, J., Li, H., and Civerolo, E. L. 2008. Identification and characterization of the Huanglongbing bacterium in pummelo from multiple locations in Guangdong, P. R. China. Plant Dis. 92:513-518.

Deng, X., Lopes, S., Wang, X., Sun, X., Jones, D., Irey, M., and Chen, J. 2014. Characterization of "Candidatus Liberibacter asiaticus" populations by double-locus analyses. Curr. Microbiol. 69:554-560.

Deng, X., and Tang, W. 1996. The studies on detection of citrus Huanglongbing pathogen by polymerase chain reaction. J. South China Agric. Univ. 17:119-120.

Duan, Y., Zhou, L., Hall, D. G., Li, W., Doddapaneni, H., Lin, H., Liu, L., Vahling, C. M., Gabriel, D. W., Williams, K. P., Dickerman, A., Sun, Y., and Gottwald, T. 2009. Complete genome sequence of citrus Huanglongbing bacterium, 'Candidatus Liberibacter asiaticus' obtained through metagenomics. Mol. Plant-Microbe Interact. 22:1011-1020.

Gan, L., and Tang, X. 2013. Guangdong Citrus. Guangdong Science and Technology Press, Guangzhou, China.

Guangdong Agriculture and Forestry College. 1977. Preliminary report of Huanglongbing transmission by citrus psyllid. Guangdong Agric. Sci. 6: 50-53.

Guangxi Citrus Huanglongbing Research Group. 1976. The pathogen of citrus Huanglongbing and the treatment with tetracycline and terramycin. South China Fruits 2:28-32.

Halbert, S. E. 2005. The discovery of Huanglongbing in Florida. Proc. 2nd Int. Citrus Canker Huanglongbing Res. Workshop H-3. Florida Citrus Mutual, Orlando, FL.

He, W. L. 1937. The citrus disease. Lingnan J. 6:135-188.

Huang, L. 1943. The citrus disease in Guangxi. Guangxi Agric. J. 4:27-61.

Jagoueix, S., Bové, J. M., and Garnier, M. 1994. The phloem-limited bacterium of greening disease of citrus is a member of the alpha subdivision of the Proteobacteria. Int. J. Syst. Bacteriol. 44:379-386.

Jiang, Z., He, F., and Wang, H. C. 1935a. Observations on the culture of oranges near Swatou, China. Lingnan Agric. J. 1:1-74.

Jiang, Z., Li, M. S., and Wang, H. Z. 1935b. Introduction of citrus cultivation in Guangdong. Lingnan Agric. J. 2:105-164.

Ke, C., Lin, Z. X., Chen, H., Chen, Y. Z., and Zhang, L. J. 1979. A preliminary report on the study of citrus Huanglongbing with Rickettsia-like organism and viruses. Chin. Sci. Bull. 24:463-466.

Ke, S., Li, K. B., Ke, C., and Cai, X. Z. 1986. The procaryote associated with citrus Huanglongbing in China is transmitted successfully from citrus to periwinkle by dodder. Fujian J. Agric. Sci. V:11-16.

Kumagai, L., Levesque, C., Blomquist, C. L., Madishetty, K., Guo, Y. Y., Woods, P., Rooney-Latham, S., Rascoe, J., Gallindo, T., Schnabel, D., and Polek, M. 2013. First report of 'Candidatus Liberibacter asiaticus' associated with citrus Huanglongbing (HLB) in California. Plant Dis. 97:283.

Kunta, M., Sétamou, M., Skaria, M., Li, W., Nakhla, M. K., and da Graça, J. V. 2012. First report of citrus Huanglongbing in Texas. (Abstr.) Phytopathology 102:S4.66.

Kuwayama, S. 1907. Die psylliden, Japans: I. Trans. Sopporo Nat. Hist. Soc. 2:149-189.
Laflèche, D., and Bové, J. M. 1970. Mycoplasma type structures in orange leaves with greening disease. C. R. Seances Acad. Sci. Ser. D 270: 1915-1917.

Li, W., Hartung, J. S., and Levy, L. 2006. Quantitative real-time PCR for detection and identification of Candidatus Liberibacter species associated with citrus Huanglongbing. J. Microbiol. Methods 66:104-115.

Lin, K. H. 1956a. Observations on yellow shoot of citrus. Acta Phytopathol. Sin. 2:1-11.

Lin, K. H. 1956b. Etiological studies of yellow shoot of citrus. Acta Phytopathol. Sin. 2:12-42.

Lin, K. H. 1957a. Further comments on Citrus Huanglongbing. Guangdong Agric. Commun. 1-2:30-32.

Lin, K. H. 1957b. Why quarantine measures should be taken for citrus yellow shoot disease (Huanglongbing). South China Agric. Sci. 1:45-47.

Lin, K. H. 1963. Further studies on citrus yellow shoot. Plant Prot. J. 2: 243-257.

Lin, K. H. 1982. Disease and Pest-Free Cultivation of Citrus. Agriculture Press, Beijing.

Lin, K. H., and Luo, X. H. 1965. A preliminary study on thermotherapy of yellow shoot disease of citrus. Acta Phytopathol. Sin. 4:169-175.

Lin, K. H., and Zheng, R. Y. 1964. A preliminary study on the resistance of yellow shoot virus and citrus budwood tissue to heat. Acta Phytopathol. Sin. 7:61-65.

Lin, K. H., and Zhu, M. 1957. The relation of Fusarium species to yellow shoot of citrus. Acta Phytopathol. Sin. 3:169-186.

Liu, R., Zhang, P., Pu, X., Xing, X., Chen, J., and Deng, X. 2011. Analysis of a prophage gene frequency revealed population variation of 'Candidatus Liberibacter asiaticus' from two citrus-growing provinces in china. Plant Dis. 95:431-435.

Lopes, S. A., Bertolini, E., Frare, G. F., Martins, E. C., Wulff, N. A., Teixeira, D. C., Fernandes, N. G., and Cambra, M. 2009. Graft transmission efficiencies and multiplication of 'Candidatus Liberibacter americanus' and 'Ca. Liberibacter asiaticus' in citrus plants. Phytopathology 99:301-306.

Lou, B., Bai, X., Bai, Y., Deng, C., RoyChowdhury, M., Chen, C., and Song, Y. 2014. Detection and molecular characterization of a 16SrII-A* phytoplasma in grapefruit (Citrus paradisi) with Huanglongbing-like symptoms in China. J. Phytopathol. 162:387-395.

Luo, X. H. 1983. Studies on the sterilization effect of the intermittent hot water treatment on citrus budwood and nursling infected with citrus yellow shoot. J. S. China Agric. Coll. 4:97-103.

Luo, X. H., Luo, Z. D., and Tang, W. W. 1981. Studies on thermotherapy of citrus yellow shoot disease. Acta Phytopathol. Sin. 8:17-52.

Ma, W., Liang, M., Guan, L., Xu, M., Wen, X., Deng, X., and Chen, J. 2014. Population structures of 'Candidatus Liberibacter asiaticus' in southern china. Phytopathology 104:158-162.

Martin, J. H., and Lau, C. S. K. 2011. The Hemiptera: Sternorrhyncha (Insecta) of Hong Kong, China-an annotated inventory citing voucher specimens and published records. Zootaxa 2847:1-122.

Planet, P., Jagoueix, S., Bové, J. M., and Garnier, M. 1995. Detection and characterization of the African citrus greening Liberobacter by amplification, cloning, and sequencing of the rplKAJL-rpoBC operon. Curr. Microbiol. 30:137-141.

Reinking, O. A. 1919. Diseases of economic plants in southern China. Philipp. Agric. 8:109-135.

Saglio, P., Laflèche, D., Bonissol, C., and Bové, J. M. 1971. Isolement, culture et observation au microscope electronique des structures de type mycoplasme associé à la maladie du stubborn des agrumes et leur comparaison avec les structures observées dans le cas de la maladie du greening des agrumes. Physiol. Veg. 9:569-582.

Selvaraj, V., Maheshwari, Y., Hajeri, S., Chen, J., McCollum, T. G., and Yokomi, R. 2018. Development of a duplex droplet digital PCR assay for absolute quantitative detection of "Candidatus Liberibacter asiaticus". PLoS One 13:e0197184.

Shanghai Institute of Biochemistry of Chinese Academy of Sciences. 1973. Research on the pathogen of citrus Huanglongbing I. A kind of linear virus related to citrus Huanglongbing. Scientia Sinica 16:313-325.

Teixeira, D., Saillard, C., Eveillard, S., Danet, J. L., da Costa, P. I., Ayres, A. J., and Bové, J. 2005. Candidatus Liberibacter americanus,' associated with citrus Huanglongbing (greening disease) in Sao Paulo State, Brazil. Int. J. Syst. Evol. Microbiol. 55:1857-1862.

Teixeira, D. C., Wulff, N. A., Martins, E. C., Kitajima, E. W., Bassanezi, R., Ayres, A. J., Eveillard, S., Saillard, C., and Bové, J. M. 2008. A phytoplasma closely related to the pigeon pea witches'-broom phytoplasma (16Sr IX) is associated with citrus Huanglongbing symptoms in the state of São Paulo, Brazil. Phytopathology 98:977-984.

Tian, Y. N., Ke, S., and Ke, C. 1996. Detection and quantitation of citrus Huanglongbing pathogen by polymerase chain reaction. Acta Phytopathol. Sin. 26:243-250. 
Tu, C. 1932. Notes on diseases of economic plants in South China. Lingnan Sci. J. 11:489-503.

Villechanoux, S., Garnier, M., Laigret, F., Renaudin, J., and Bové, J. M. 1993. The genome of the non-cultured, bacterial-like organism associated with citrus greening disease contains the nusG-rplKAJL-rpoBC gene cluster and the gene for a bacteriophage type DNA polymerase. Curr. Microbiol. 26: 161-166.

Villechanoux, S., Garnier, M., Renaudin, J., and Bové, M. 1992. Detection of several strains of the bacterium-like organism of citrus greening disease by DNA probes. Curr. Microbiol. 24:89-95.

Wang, X., Tan, J., Bai, Z., Su, H., Deng, X., Li, Z., Zhou, C., and Chen, J. 2013. Detection and characterization of miniature inverted-repeat transposable elements in "Candidatus Liberibacter asiaticus". J. Bacteriol. 195: 3979-3986.

Wang, X., Zhou, C., Deng, X., Su, H., and Chen, J. 2012. Molecular characterization of a mosaic locus in the genome of 'Candidatus Liberibacter asiaticus'. BMC Microbiol. 12:18.

Wu, F., Zheng, Z., Deng, X., Cen, Y., Liang, G., and Chen, J. 2015. Draft genome sequence of "Candidatus Liberibacter asiaticus" from Diaphorina citri in Guangdong, China. Genome Announc. 3:e01316-15.
Zhao, X. Y. 2017. A review of the prevention and control of Citrus Huanglongbing. China Agriculture Press, Beijing.

Zhao, X. Y., Jiang, Y. H., Qiu, Z. S., and Li, B. M. 1979. Tristeza indexing of the plants affected with citrus yellow shoot. S. China Fruits 3:33-34. (In Chinese)

Zheng, Z., Bao, M., Wu, F., Chen, J., and Deng, X. 2016a. Predominance of single prophage carrying a CRISPR/cas System in "Candidatus Liberibacter asiaticus" strains in southern China. PLoS One 11:e0146422.

Zheng, Z., Bao, M., Wu, F., Van, H. C., Chen, J., and Deng, X. 2018. A type 3 prophage of 'Candidatus Liberibacter asiaticus' carrying a restrictionmodification system. Phytopathology 108:454-461.

Zheng, Z., Deng, X., and Chen, J. 2014. Whole-genome sequence of "Candidatus Liberibacter asiaticus" from Guangdong, China. Genome Announc. 2:e00273-e14.

Zheng, Z., Wu, F., Kumagai, L., Polek, M., Deng, X., and Chen, J. 2017. Two 'Candidatus Liberibacter asiaticus' strains recently found in California harbor different prophages. Phytopathology 107:662-668.

Zheng, Z., Xu, M., Bao, M., Wu, F., Chen, J., and Deng, X. 2016b. Unusual five copies and dual forms of nrdB in "Candidatus Liberibacter asiaticus": Biological implications and PCR detection application. Sci. Rep. 6: 39020. 